\title{
LIGHTNING ACTIVITY CHARACTERISTICS UNDER COMPLEX TOPOGRAPHY IN LOW LATITUDE PLATEAU OF CHINA
}

\author{
YIN, L. Y. ${ }^{1,2}-$ WANG, H. Y. ${ }^{1,3}-$ JIN, W. J. ${ }^{2}$-ZHANG, S. D. ${ }^{1}-$ WANG, W. G. ${ }^{1 *}-$ MEI, H. ${ }^{2}$ \\ ${ }^{I}$ Department of Atmospheric Sciences, Yunnan University, Kunming 650500, P. R. China \\ ${ }^{2}$ Weather Modification Center of Yunnan Province, Kunming 650034, P. R. China \\ ${ }^{3}$ Department of Environmental Science \& Engineering, Shanghai Key Laboratory of \\ Atmospheric Particle Pollution and Prevention, Fudan University \\ 220 Handan Road, Shanghai 200433, P. R. China \\ *Corresponding author \\ e-mail:wangwg@ynu.edu.cn \\ (Received 31 $1^{\text {st }}$ May 2018; accepted $2^{\text {nd }}$ Aug 2018)
}

\begin{abstract}
Comparison analysis was performed for the characteristics of cloud-to-ground (CG) lightning and topography in low latitude plateau of China and showed that CG lightning activity was characterized Gaussian distribution along the variation of elevation centered at approximately $2000 \mathrm{~m}$ above sea level and decreased on both sides; it was also linearly inversely correlated with variations in terrain slope. CG lightning activity was showed a typical positive dipole distribution of electric charges in the thunderstorm clouds. The average current intensity of negative CG lightning located in the lower layers was obviously weaker than that of the positive CG lightning located in the upper layers, and decreased initially and subsequently increased as the elevation increased, whereas the positive CG lightning had no significant variation. The CG lightning current intensity increased linearly with terrain slope, and the variation slope of positive CG lightning was smaller than that of negative CG lightning, variation of current intensity with latitude was inversely correlated with the variation of CG lightning densities. The CG lightning activity and variation of current intensity had the same characteristics in specific regions and in zonal and meridional cross-sections, but it was significantly affected by the topography in the low/high regions where elevation was $<600 />3500 \mathrm{~m}$.
\end{abstract}

Keywords: cloud-to-ground (CG) lightning, elevation, terrain slope, effect of topography

\section{Introduction}

Terrain topography can greatly affect the movement and development of the general circulation of the atmosphere, particularly convergence systems, fronts, and typhoons (Egger et al., 1992; Smith, 1979). Smith (1979) proposed using linear regression to describe the correlation between annual average precipitation and altitude; studies have used linear regression to describe the linear correlation between lightning and precipitation (Ezcurra et al., 2002; Jayaratne and Kuleshov, 2006; Soula and Chauzy, 2001). Without considering the formation mechanisms of lightning, precipitation, and other factors, topography has an obvious influence on precipitation and lightning activity. Topography can directly or indirectly affect the direction of the local prevailing wind, and in appropriate conditions, different elevations and terrain slopes can directly affect updrafts, resulting in strong weather, such as barrier jets and thunderstorms, which are usually accompanied by obvious precipitation and lightning activity. Researchers have also employed numerical model simulations to find that topography has a great influence on lightning activity (Smith, 1979). 
Researchers have found that topography can affect the spatial and temporal distributions of lightning. Pinto Jr. et al. (1999) analyzed the spatial distribution of lightning in southern Brazil and found a favorable correlation between topography and lightning activity, and Schulz and Diendorfer (1999) revealed a nonlinear correlation between topography and lightning activity: cloud-to-ground (CG) lightning activity increased linearly as elevation increased, whereas the CG lightning decreased linearly as elevation increased for elevation $>1300 \mathrm{~m}$. Wagner et al. (2006) found a favorable correlation between topography, wind direction, and CG lightning flash count in the United States, and Zajac and Rutledge (2001) analyzed the relationships between CG lightning flash density, thunderstorm days, topography, and other meteorological parameters, which showed favorable correlations between the topography, CG lightning flash density, and thunderstorm days in the United States. Bourscheidt (2009) analyzed data on lightning records from 2005 to 2007 in Brazil and found that terrain slope had a highly significant influence on lightning flash distribution. In China, Ma et al. (2004) analyzed 6 years of lightning data recorded using a satellite-equipped optical transient detector (May 1995-March 2000) and lightning imaging sensors (December 1997March 2003) and obtained the distribution of lightning density in this area with a grid format of $0.5^{\circ} \times 0.5^{\circ}$, which showed significant regional differences in lightning density in mainland China: as with different geographic environments, the high lightning density areas (centers) have different relationships to mesoscale topography. Tong et al. (2008) analyzed the characteristics of lightning activity in Zhejiang Province by using a map of CG lightning density as measured by a lightning coordination system from 2004 to 2007; their study showed a correlation between topography, seasonal climate, and lightning activity. Qie et al. (2003) compared the lightning activity of typical topographies globally using lightning coordination data measured by the lightning detection system on the Tropical Rainfall Measuring Mission satellite, and the results showed significant differences in lightning activities both in lightning flash count and lightning intensity in different topographic regions. Qie et al. (2009) analyzed the electrical characteristics of thunderstorms in different elevations and found that the special-type thunderstorm was positively related to the elevation of the region, in the Chinese Inland Plateau, the height of the charge region neutralized by negative CG flashes ranges from $3 \mathrm{~km}$ to $5 \mathrm{~km}$ above the ground, corresponding to an ambient temperature between -2 and $-15^{\circ} \mathrm{C}$. For the two positive $\mathrm{CG}$ flashes, the neutralized charge regions are located at a height of about $5.5 \mathrm{~km}$ and the ambient temperature is about $-18{ }^{\circ} \mathrm{C}$, indicating the existence of upper positive charge in the thunderstorm. Qie et al. (2013), Wang et al. (2016) analyzed the lightning activity in northeastern China, and the results showed lightning events mainly occurred in regions with a large gradient of CAPE. Comparisons between lightning and non-lightning regions indicated that lightning regions featured more intense ascending motion than non-lightning regions.

Yunnan Province is in the southwestern border region of China, and it has the typical geographic characteristics of a low latitude plateau with the terrain descending from the northwest to the southeast; it has unusually great elevational differences; the maximum elevation difference can be more than $6000 \mathrm{~m}$. Yunnan has frequent CG lightning activity throughout the year, with uneven temporal and spatial distributions (Xie et al., 2013). In the present study, Lightning activity characteristics under complex topography in low latitude plateau was analyzed using 10 years of CG lightning records from 2007 to 2016 and detailed geographic elevation data from Yunnan Province of China. 


\section{Data and methods}

The CG lightning data were recorded by the Lightning Detection and Coordination Network based on 22 ADTD (ADvanced TOA and Direction) lightning locators and a central data processing station that provided information on each lightning flash, including time, location, intensity, and polarity, with theoretical coordinating accuracy and detection efficiency of approximately $500 \mathrm{~m}$ and $95 \%$, respectively. The CG lightning data were not corrected for efficiency.

The topography data comprised a Digital Elevation Model (DEM) measured by the Shuttle Radar Topography Mission (SRTM), with two datasets, SRTM1 and SRTM3, with precisions of 1 arcsecond and 3 arcseconds, respectively. Of these datasets, SRTM3 can cover the globe and is the most widely used topographic dataset. The spatial resolution of the SRTM3 data discussed in this article was $3 \mathrm{~s}$. Its elevation datum was the EGM96 geoid with an accuracy of $\pm 16 \mathrm{~m}$, and the horizontal datum was the WGS 84 with a horizontal accuracy of $\pm 20 \mathrm{~m}$. Positive CG lightning whose intensity was less than $20 \mathrm{kA}$ was expelled as cloud-to-cloud lightning (Biagi et al., 2007).

Terrain slope is the degree of inclination compared with the horizontal plane of a point on the ground that can be calculated from the value of the elevation of two adjacent points using DEM data. It is defined as the angle between the tangential plane and the horizontal ground at this point (Monmonier, 1982); the exact calculation formula is

$$
s l p=\sqrt{\left(\frac{\text { right }- \text { left }}{\text { res } * 2}\right)^{2}+\left(\frac{\text { top }- \text { bottom }}{\text { res } * 2}\right)^{2}} .
$$

Within this formula, top, bottom, right, and left represent the elevations of the adjacent points, respectively, to the top, bottom, right, and left; res represents the distance between two adjacent points, and the units of all these parameters are, m. $\tan ^{-1}(s l p)$ is used in this article to describe the inclination to the horizontal plane as the terrain slope.

The latitude and longitude in the present study ranged from $20.5^{\circ} \mathrm{N}$ to $29.5^{\circ} \mathrm{N}$ and from $95.5^{\circ} \mathrm{E}$ to $106.6^{\circ} \mathrm{E}$, and the CG lightning data were integrated into the statistics as a grid with an accuracy of $0.01^{\circ}$, and the average elevation was taken as the elevation value of the grid to analyze the CG lightning activity characteristics.

\section{Results}

\section{Topographic variation and lightning density characteristics}

Figure $1 a$ is the map of elevation with an accuracy of $0.01^{\circ} \times 0.01^{\circ}$. Yunnan of China is located in the junction region of the southeastern margin of the Tibetan Plateau and the Yunnan-Guizhou Plateau, a region which is mainly mountains and plateaus with low latitude and high elevation. The terrain is highest in the northwest and descends toward the southeast and stretches toward the east, southeast, south, southwest, and west in a fingerlike fashion. In northwestern Yunnan, the terrain is an obvious fold mountain area with sharp rises and drops in elevation because the elevations of the valleys of the Three Parallel Rivers are lower than $1500 \mathrm{~m}$, whereas those of the snow mountains exceed 5000 m; the Kawakarpo Peak of the Meili Snow 
Mountain is the highest point in Yunnan Province, ascending to $6740 \mathrm{~m}$. Except for the northwestern part, the terrain of Yunnan Province can be divided into two major regions with the fault area of the Ailao Mountains as the boundary; to the west are the highlands with moderate- and high-elevation mountains as the main terrain. This highland region contains a high concentration of mountains; to the north of the Wuliang Mountain, all the mountaintops are higher than $2500 \mathrm{~m}$, whereas the heights gradually decrease to the south. In the region to the east of the Ailao Mountains, the Honghe Valley and Yuanjiang Valley stretch alongside the Ailao Mountains; the elevation declines rapidly as the valleys stretch southward, and the lowest point is only $76.4 \mathrm{~m}$ high. The elevation is relatively high further east and it declines gradually to the southeastern part of Wenshan Autonomous Prefecture. Further north is an area of plateaus and hills whose elevations are relatively high, fluctuating from 1800 to $3000 \mathrm{~m}$; this area stretches northeast to the northern part of Zhaotong City where the elevation declines rapidly. The slope features of terrain in Yunnan Province are also divided by the Ailao Mountains (see Fig. 1b); the east is the flattest area in Yunnan, dominated by basins and hills, and corresponding to the mid-altitude regions, mostly with an elevation of 1500 $3000 \mathrm{~m}$. To the southwest of the Ailao Mountains is the second region of mild terrain slope. The elevation of this region varies to a greater extent than do theentral and eastern areas of Yunnan, which have elevations between 1000 and $2000 \mathrm{~m}$. The terrain slope of the rest of the region is more complicated and follows the trend of the mountains, and the deviation to the Hengduan Mountains in the northwestern Yunnan is severe. Affected by this topography, the CG lightning density has a typical spatial distribution along the mountains' trends (see Fig. $1 c$ ).

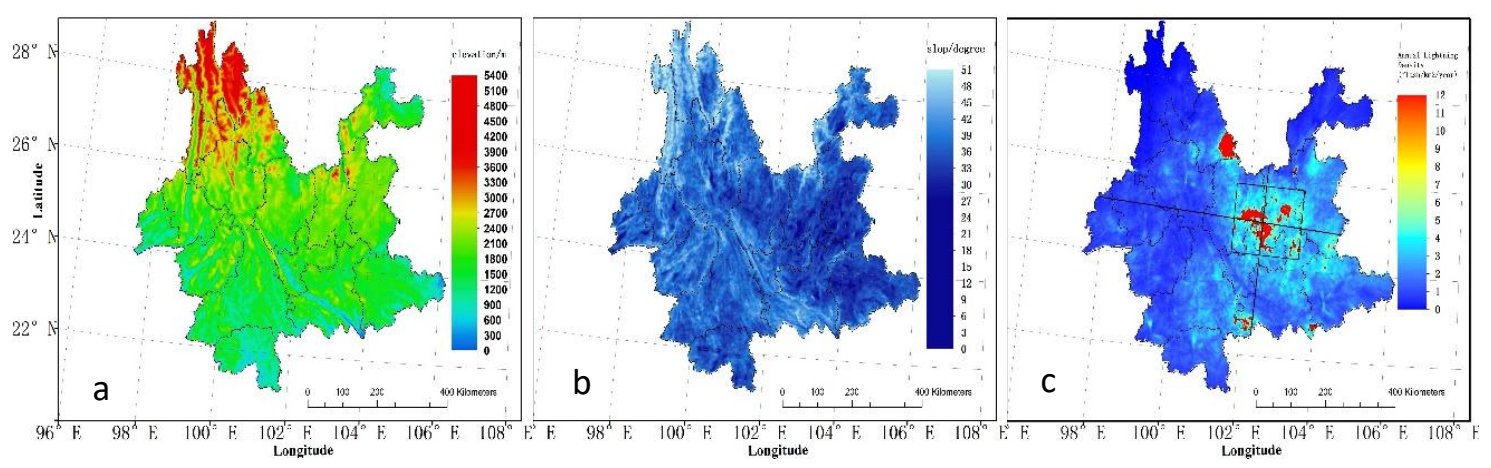

Figure 1. Map of elevation and annual average CG lightning density distribution of Yunnan Province. a: elevation (m); $b$ : terrain slope (degree); $c$ : CG lightning density (time/year $\bullet \mathrm{km}^{2}$ )

The area with the highest CG lightning density was in the central region of Yunnan, northeast of the Ailao Mountains, which features relatively flat and unobvious folded topography with elevations of 1800-2500 m. Synoptic analysis showed that this region was mainly affected by cold front shear, convergence shear, and other synoptic systems. The frequent convergence of cold and warm air made this region suitable for forming large-scale strong convective weather systems ( $\mathrm{Li}, 2011$; Xu et al., 2011). The secondhighest CG lightning density area was in Huaping County, Lijiang City, northwestern Yunnan, which is surrounded by mountains higher than $3100 \mathrm{~m}$ to the north, west, and south, whereas the elevation of the high density area is lower than $2000 \mathrm{~m}$. Furthermore, to the east of this area lie the Hengduan Mountains at the Yunnan-Sichuan border, which the plateau trough and southwestern vortex cross when moving southeastward 
into northwestern Yunnan; consequently, an obvious upward stream was formed, thus creating this high CG lightning density area (Li, 2011; Xu et al., 2011). The thirdhighest CG lightning density area was located in southeastern Pu'er City, which is on the southwestern side of the Ailao Mountains. This area was dominated by warm and humid air flow that could form an upward stream due to the topographic uplift effect. The blockading effect of the Ailao Mountains weakens the effect of cold air in this area; thus, the lightning activity is relatively weak ( $\mathrm{Li}, 2011 ; \mathrm{Xu}$ et al., 2011). In the valley regions to the western side of the Ailao Mountains and in the low-elevation regions in northeastern and eastern Yunnan (elevation $<1000 \mathrm{~m}$, flat topography, and with no mountains higher than $3000 \mathrm{~m}$ ), the CG lightning activity is relatively weak. The highelevation regions (elevation $>3500 \mathrm{~m}$ with obvious folded topography) and northeastern Yunnan, where the effects of warm and humid airstreams are minimal, are nearly zerozones for CG lightning activity.

\section{Distribution of topographic variation and lightning density}

The distribution of CG lightning at different elevations was determined by analyzing the statistics on CG lightning flashes from 2007 to 2016, with $100 \mathrm{~m}$ as the elevation increment unit. The result (see Fig. 2a) showed that total CG lightning flashes were normally distributed with elevation and mainly appeared in the area between 800 and $3300 \mathrm{~m}$. Within this range of elevation, the area of the corresponding regions accounts for $90.6 \%$ of the land area of Yunnan Province, where $96 \%$ of the total CG lightning occurred; in particular, in the regions with elevations between 1900 and $2100 \mathrm{~m}$, the number of CG lightning flashes reached 1.56 million.

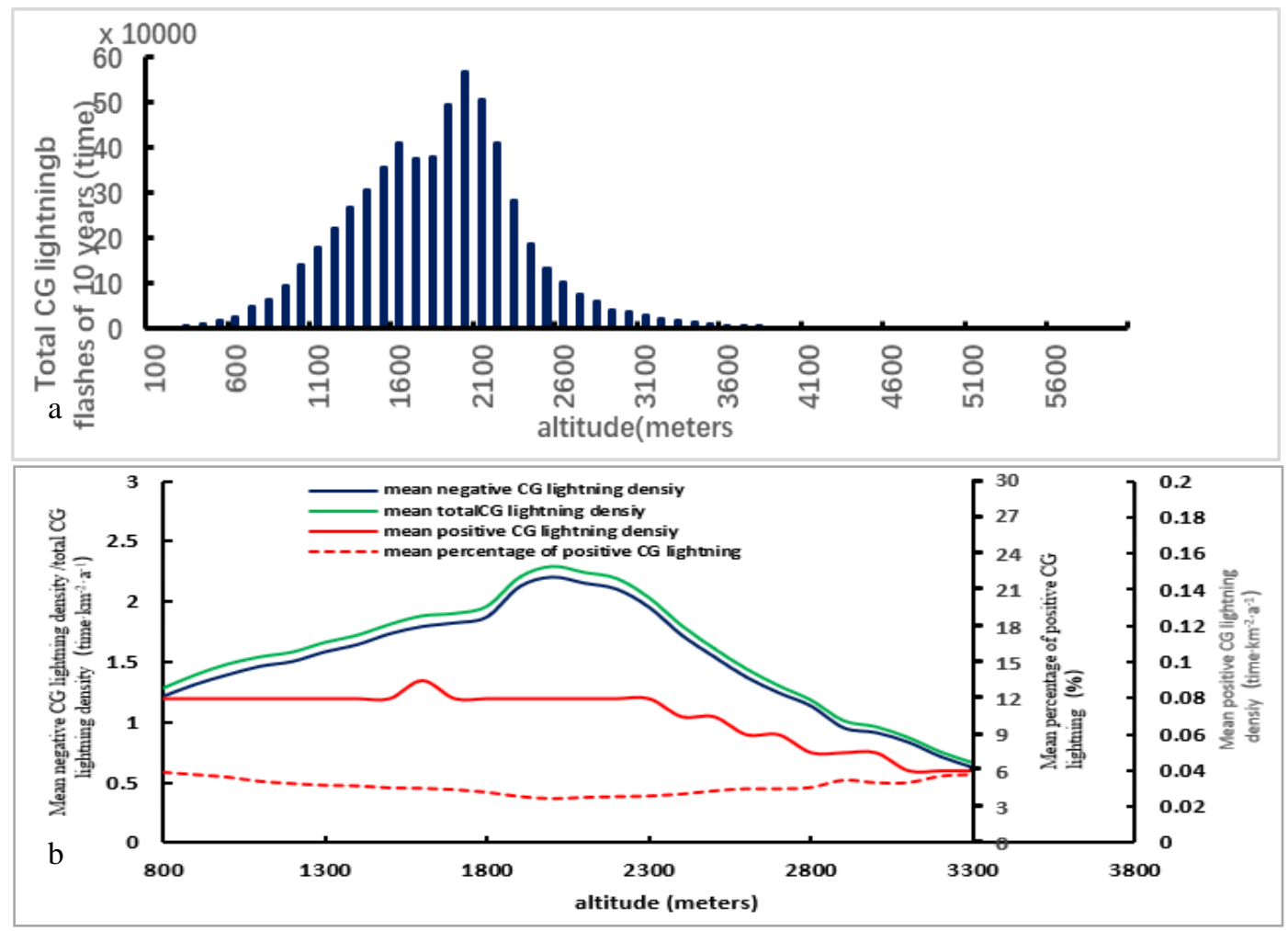

Figure 2. distribution of elevation variation and total CG lightning counts, average CG lightning density and the proportion of positive CG lightning (a: variation of total CG lightning counts; $b$ : variation of $C G$ lightning density and proportion of positive CG lightning) 
The regions with elevation $<800 \mathrm{~m}$ account for $3.7 \%$ of the land area of Yunnan Province, and only $3 \%$ of the CG lightning flashes were recorded in these regions, whereas regions with elevation $>3300 \mathrm{~m}$ account for $5.7 \%$ of the land area, and only $1 \%$ of the CG lightning flashes were recorded in these regions. Therefore, the CG lightning activity in regions $<800 \mathrm{~m}$ or $>3300 \mathrm{~m}$ was unrepresentative; thus, only the effect of elevation within the range of 800 to $3300 \mathrm{~m}$ on CG lightning activity was analyzed (see Fig. 2b). The average total CG lightning density and average negative CG lightning density corresponded to the trend of elevation, which exhibited unimodal variation with the peak in the 1900-2000-m range where the average total CG lightning density peaked at 2.29 events $\cdot \mathrm{km}^{-2} \cdot \mathrm{a}^{-1}$ and the average negative CG lightning density peaked at 2.2 events $\cdot \mathrm{km}^{-2} \cdot \mathrm{a}^{-1}$, whereas the average positive CG lightning density was stable at $0.08-2.2$ events $\cdot \mathrm{km}^{-2} \cdot \mathrm{a}^{-1}$ from 800 to $2000 \mathrm{~m}$. As the elevation increased, the average total/negative CG lightning density decreased linearly, the average positive CG lightning density fluctuated between 0.06 and 0.08 events $\cdot \mathrm{km}^{-2} \cdot \mathrm{a}^{-1}$, and the average total/negative (positive) CG lightning densities exhibited fluctuating reduction when elevation $>2300 \mathrm{~m}$. Land area increased linearly as elevation increased when elevation $<1600 \mathrm{~m}$, fluctuated at approximately $1800 \mathrm{~m}$, and peaked between 1900 and $2000 \mathrm{~m}$. This phase corresponded to the peak value of average negative/total CG lightning densities, and the average positive CG lightning density was stable in this area, exhibiting frequent CG lightning activity at the elevation band of 1900-2000 m, where the convergence of cold and warm air frequently occurs.

As can be seen from the variation characteristics of positive CG lightning and elevation, the average percentage of positive CG lightning was only approximately 5\%, there was bipolar structural characteristics of thunderstorms in Yunnan Province because the center of negative charge is close to the ground and the center of positive charge is located at high layers. Positive CG lightning exhibited slow fluctuating reductions as the elevation increased from 800 to $2000 \mathrm{~m}$, and the proportion of them was at a minimum of $3.69 \%$ at approximately $2000 \mathrm{~m}$, which corresponded to the peak value of negative CG lightning activity. This indicated that the negative charge of the thunderstorm cloud was abnormally active in the area of cold and warm air interaction. In the range of 2000-3300 m above sea level, the proportion of positive CG lightning flashes fluctuating increased as the elevation increased, indicating a significant difference between the excitation conditions of positive/negative CG lightning flashes in the high- and low-altitude regions and the excitation conditions in the mid-altitude (1900-2000 m) regions where negative CG lightning flashes were concentrated.

\section{Distribution of terrain slope and CG lightning density}

The terrain slope has a promoting effect on airflow uplift and convection. Statistics on average CG lightning density for each slope section of $1^{\circ}$ were analyzed (see Fig. 3), and the results showed that CG lightning activity increased rapidly and decreased linearly after peaking as the terrain slope increased, and the total CG lightning count significantly decreased when the tendency declined as the terrain slope continued to steepen more than $20^{\circ}$. CG lightning was mainly concentrated in the slope sections between $0^{\circ}$ and $30^{\circ}$, where $98.6 \%$ of the total CG lightning occurred; these sections contained $97.7 \%$ of the total land area of Yunnan Province, particularly the sections between $0^{\circ}$ and $5^{\circ}$ where CG lightning was most active and where the 10 -year total count reached 2.75 million, approximately $46 \%$ of the total CG lightning count. These sections contained approximately $37 \%$ of the total land area. Only $3 \%$ of total CG 
lightning occurred within the slope sections steeper than $30^{\circ}$, which constituted only $1.3 \%$ of the total land area, indicating that within the range of $1 \mathrm{~km}^{2}$, regions with terrain slope $>30^{\circ}$ were few and the CG lightning in these regions was too infrequent to be further analyzed. Thus, the analysis of the effects of terrain slope on CG lightning density and the proportion of the positive lightning in Figure $3 b$ consisted only of the sections less than $30^{\circ}$.

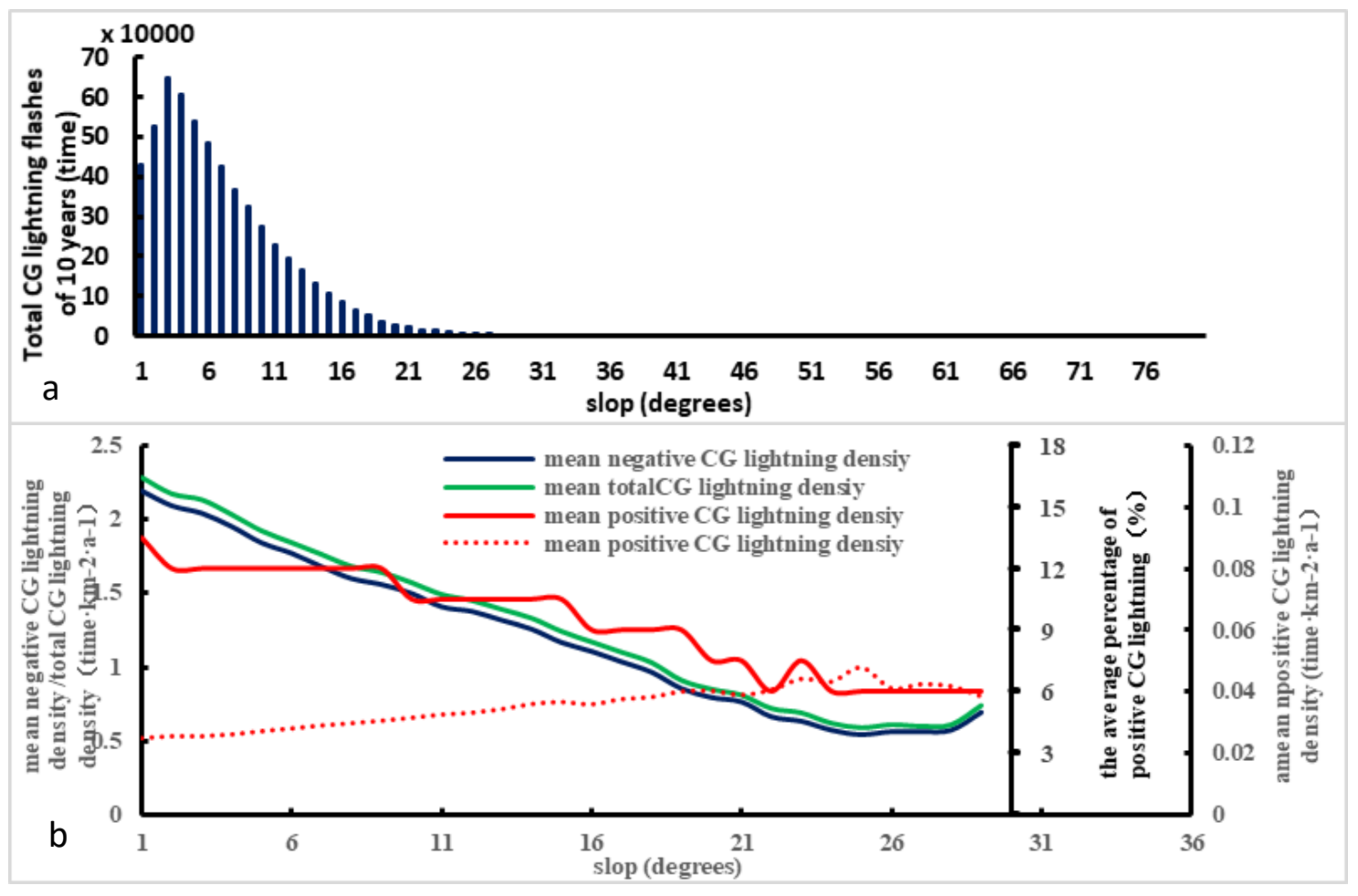

Figure 3. Variations in total CG lightning counts, average CG lightning densities, and the proportion of positive CG lightning over terrain slope of 2007-(2016). a: Variation of total CG lightning counts over terrain slope; $b$ : variations of average CG lightning densities and the proportion of positive CG lightning over terrain slope

The average total/negative CG lightning density peaked $\left(2.28\right.$ events $\cdot \mathrm{km}^{-2} \cdot \mathrm{a}^{-1}$ and 0.57 events $\left.\cdot \mathrm{km}^{-2} \cdot \mathrm{a}^{-1}\right)$ at a slope of $1^{\circ}$ and declined linearly as slope steepened and reached a minimum $\left(0.6\right.$ events $\cdot \mathrm{km}^{-2} \cdot \mathrm{a}^{-1}$ and 0.57 events $\left.\cdot \mathrm{km}^{-2} \cdot \mathrm{a}^{-1}\right)$ at a slope of $27^{\circ}$. As the terrain slope steepened, the average total/negative CG lightning density increased again. These findings, as well as the topographic characteristics of Yunnan Province, indicated that $90 \%$ of the land was undulating plateau with many south-northward mountains and that the synoptic systems of the strong convection in Yunnan come mainly from the east to the west and create thunderstorms because of the uplift airflow affected by the terrain slope, causing an increase in CG lightning activity in regions of slope $>27^{\circ}$. Overall, the average positive CG lightning density declined in the performance of the staircase-like trend as the slope increased. At a slope of $1^{\circ}$, the average positive CG lightning peaked $\left(0.9\right.$ events $\left.\cdot \mathrm{km}^{-2} \cdot \mathrm{a}^{-1}\right)$ and subsequently dropped at $10^{\circ}, 16^{\circ}$, and $20^{\circ}$, and after a slight increase at a slope of approximately $23^{\circ}$, it remained at approximately 0.04 events $\mathrm{km}^{-}$ ${ }^{2} \cdot \mathrm{a}^{-1}$. The downward trend in CG lightning density indicated the smaller decline for positive CG lightning density and an obvious positive correlation between the 
proportion of positive CG lightning and the terrain slope. Furthermore, a comparison between elevation and terrain slope in Yunnan Province indicated that regions with slope $>27^{\circ}$ and elevation $>3000 \mathrm{~m}$ corresponded favorably. The uplift airflow caused by the windward slope of the mountains accelerated convection development, and this, combined with the rate of precipitation, reduced negative charges in the lower part of the cloud during the falling process (Biagi, 2007). This resulted in precipitation current formation, thereby reducing the frequency of low-level negative CG lightning and indirectly resulting in an increase in positive CG lightning in regions of high elevation and terrain slope.

\section{Variation in CG lightning densities and terrain slope at different elevations}

Bourscheidt's (2009) research on the variation in CG lightning density as terrain slope changed in Brazil was limited to elevations $<1000 \mathrm{~m}$, with the result that the CG lightning density increased linearly with increases in terrain slope, which was contrary to the conclusion reached in this paper. To further analyze the relationship between CG lightning density and terrain slope at different elevations, elevation was divided into four bands: $0-1500 \mathrm{~m}, 1500-2300 \mathrm{~m}, 2300-4000 \mathrm{~m}$ and $>4000 \mathrm{~m}$, and the variations in the CG lightning density with terrain slope were analyzed for the four bands (see Fig. 4).

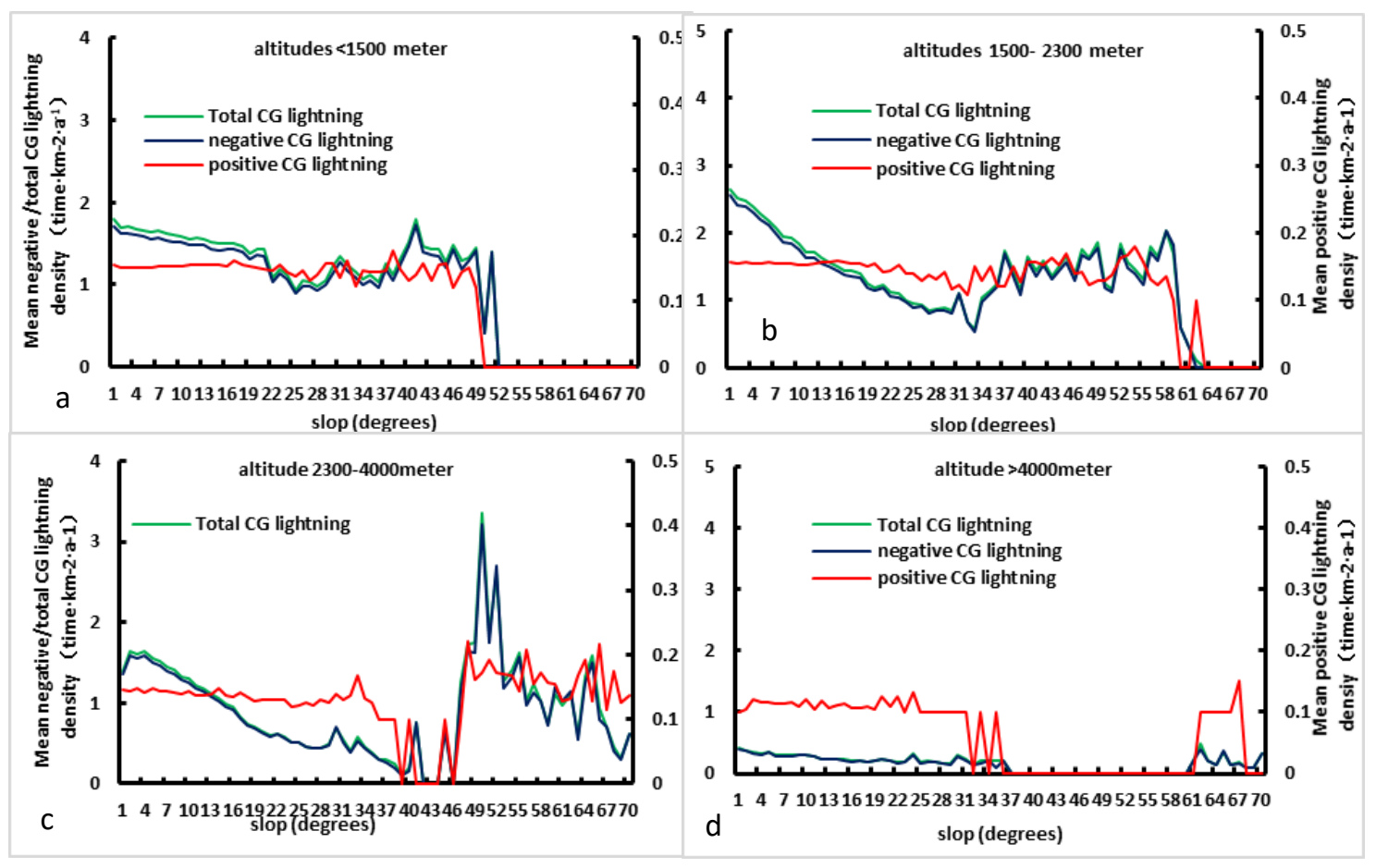

Figure 4. Variations in average total/negative and positive CG lightning densities over terrain slope at different elevations. a: $<1500 \mathrm{~m} ; \mathrm{b}: 1500-2300 \mathrm{~m} ; \mathrm{c}: 2300-4000 \mathrm{~m} ; \mathrm{c}:>4000 \mathrm{~m}$

In the $<1500 \mathrm{~m}$ band, the average total/negative CG lightning densities decreased linearly as the terrain slope increased from $0^{\circ}-25^{\circ}$ and peaked at $1.79 / 1.7$ events $\cdot \mathrm{km}^{-2} \cdot \mathrm{a}^{-}$ ${ }^{1}$ at a slope of $1^{\circ}$. It subsequently reached a minimum of $0.93 / 0.9$ events $\cdot \mathrm{km}^{-2} \cdot \mathrm{a}^{-1}$ at a slope of $25^{\circ}$. Subsequently, as the terrain slope steepened, the average total/negative CG 
lightning densities also increased, fluctuating between slopes of $25^{\circ}$ and $50^{\circ}$; within this range, the average total/negative CG lightning densities exceeded 1 events $\cdot \mathrm{km}^{-2} \cdot \mathrm{a}^{-1}$ and exhibited many peaks, with terrain slope having a strengthened uplift effect on airflow. Subsequently, the average total/negative CG lightning densities dropped rapidly for slopes of $>52^{\circ}$. The trend of average positive CG lightning density was consistent with the trend of average total/negative CG lightning densities because average positive CG lightning decreased slowly and linearly as terrain slope increased in flat (slopes $<25^{\circ}$ ) regions and fluctuated between $25^{\circ}-50^{\circ}$. Additionally, CG lightning activities tended to decrease for slopes $>45^{\circ}$. Within the 1500-2300 m band, which constitutes the largest proportion of land area (total 58\% of land area and $49 \%$ of land area), the tendency of average CG lightning was consistent with the lower elevation band. The average total/negative CG lightning densities peaked $\left(3.64 / 0.9\right.$ events $\cdot \mathrm{km}^{-2} \cdot \mathrm{a}^{-1}, \quad 2.55 / 0.9$ events $\left.\cdot \mathrm{km}^{-2} \cdot \mathrm{a}^{-1}\right)$ where the terrain slope was $1^{\circ}$ and reached a minimum $(0.57 / 0.9$ events $\cdot \mathrm{km}^{-2} \cdot \mathrm{a}^{-1}, 0.52 / 0.9$ events $\left.\cdot \mathrm{km}^{-2} \cdot \mathrm{a}^{-1}\right)$ where the terrain slope was $33^{\circ}$. Additionally, they fluctuated between the terrain slope range of $34^{\circ}-59^{\circ}$ and tended to decrease when terrain slope $>60^{\circ}$. The average positive CG lightning density was consistent with the trend of total/negative CG lightning density, except for fluctuation in flat terrain $\left(0^{\circ}-\right.$ $30^{\circ}$ ), where the positive CG lightning density remained approximately 0.15 events $\cdot \mathrm{km}^{-}$ ${ }^{2} \cdot \mathrm{a}^{-1}$. The topographic distribution in the 2300-4000 m elevation band exhibited twostage differentiation, and the variation in the average $\mathrm{CG}$ lightning density showed consistent characteristics of a linear decrease for slopes of $1^{\circ}-20^{\circ}$. The variation in the average CG lightning density land area (where terrain slope ranged from $20^{\circ}$ to $36^{\circ}$ ) decreased rapidly, but the lightning activity remained stable, resulting in peaks in the average CG lightning density. No land had a slope in the range from $37^{\circ}$ to $45^{\circ}$, and regions with terrain slope $>45^{\circ}$ comprised just $1 \%$ of the land area and total $\mathrm{CG}$ lightning count. Additionally, the small sample size resulted in larger average total/negative and positive CG lightning densities, indicating that greater terrain slope was favorable for updraft uplift and formation of local lightning activity and convection. The CG lightning density was less than 0.4 where the elevation $>4000 \mathrm{~m}$, and topography and lightning activity also exhibited two-stage differentiation.

The CG lightning activity and elevation in Yunnan Province were normally distributed but inversely correlated with the slope. Within all the elevation bands, when slopes were less steep, the CG lightning activity was relatively dense as long as the terrain slope remained smaller than $30^{\circ}$. In regions with elevation $<2300 \mathrm{~m}$ and slope of $30^{\circ}-59^{\circ}$, a small peak occurred due to the topographic uplift effect of airflow, and almost no CG lightning activity was recorded in the mountain regions where slope $>60^{\circ}$. Regions whose elevation $>2300 \mathrm{~m}$ comprised gentle basins and high mountains, causing a blank zone of CG lightning activity between the terrain slope range of $40^{\circ}-$ $55^{\circ}$. Scattered CG lightning activity occurred in greater terrain slopes, further indicating the importance of topography on CG lightning activity in Yunnan Province.

\section{Latitude and lightning density distribution}

Studies have determined that the total lightning density gradually decreases from low latitudes to high latitudes, and the proportion of CG lightning within the total lightning also decreases gradually from low latitudes to high latitudes (Chen, 2003). At a given elevation, the convective clouds in low latitudes are more active, resulting in higher CG lightning densities than in the high latitudes. Figure $5 a$ shows the distribution of average CG lightning density by latitude with a resolution of $0.01^{\circ}$ for Yunnan Province 
from 2007 to 2016, showing that the average total/negative CG lightning densities tended to increase first and subsequently decrease with multiple peaks as latitude increased. The first peak appeared at $22.8^{\circ} \mathrm{N}$, and the average total/negative $\mathrm{CG}$ lightning density was $1.72 / 1.66$ events $\cdot \mathrm{km}^{-2} \cdot \mathrm{a}^{-1}$. The two regions with CG lightning densities larger than 12 events $\cdot \mathrm{km}^{-2} \cdot \mathrm{a}^{-1}$ within this latitude band were located to the west of the Ailao Mountains and to the east of Honghe Valley where the elevation rises from the west to the east. Subsequently, the average total/negative CG lightning density dropped rapidly within the mountainous region of the Ailao Mountains and the lower regions where elevation $<1800 \mathrm{~m}$. The second peak in average total/negative CG lightning density appeared between $24^{\circ} \mathrm{N}-25.2^{\circ} \mathrm{N}$ with density sustained at $1.6-1.8$ events $\cdot \mathrm{km}^{-2} \cdot \mathrm{a}^{-1}$; these regions corresponded to the convergence area of cold and warm air to the east of the Ailao Mountains, where the low $0{ }^{\circ} \mathrm{C}$ layer, sufficient moisture, and strong uplift airflow caused a high negative lightning density. The third peak in average total/negative CG lightning densities appeared at approximately $26.5^{\circ} \mathrm{N}$, located near the Hengduan Mountains by the Yunnan-Sichuan boundary, which was also one pathway for the intruding cold air. Subsequently, the average total/negative CG lightning density dropped rapidly as the latitude increased. Compared with the average total/negative CG lightning density, the average positive CG lightning density was approximately one order of magnitude less, and the trend of variation almost corresponded to the average total/negative CG lightning except that the third peak was obviously southward. To further analyze the relationship between the CG lightning densities and latitude of the dense CG lightning area (1900-2100 m), the variation in CG lightning density by latitude in this elevation band is shown in Figure $5 b$.

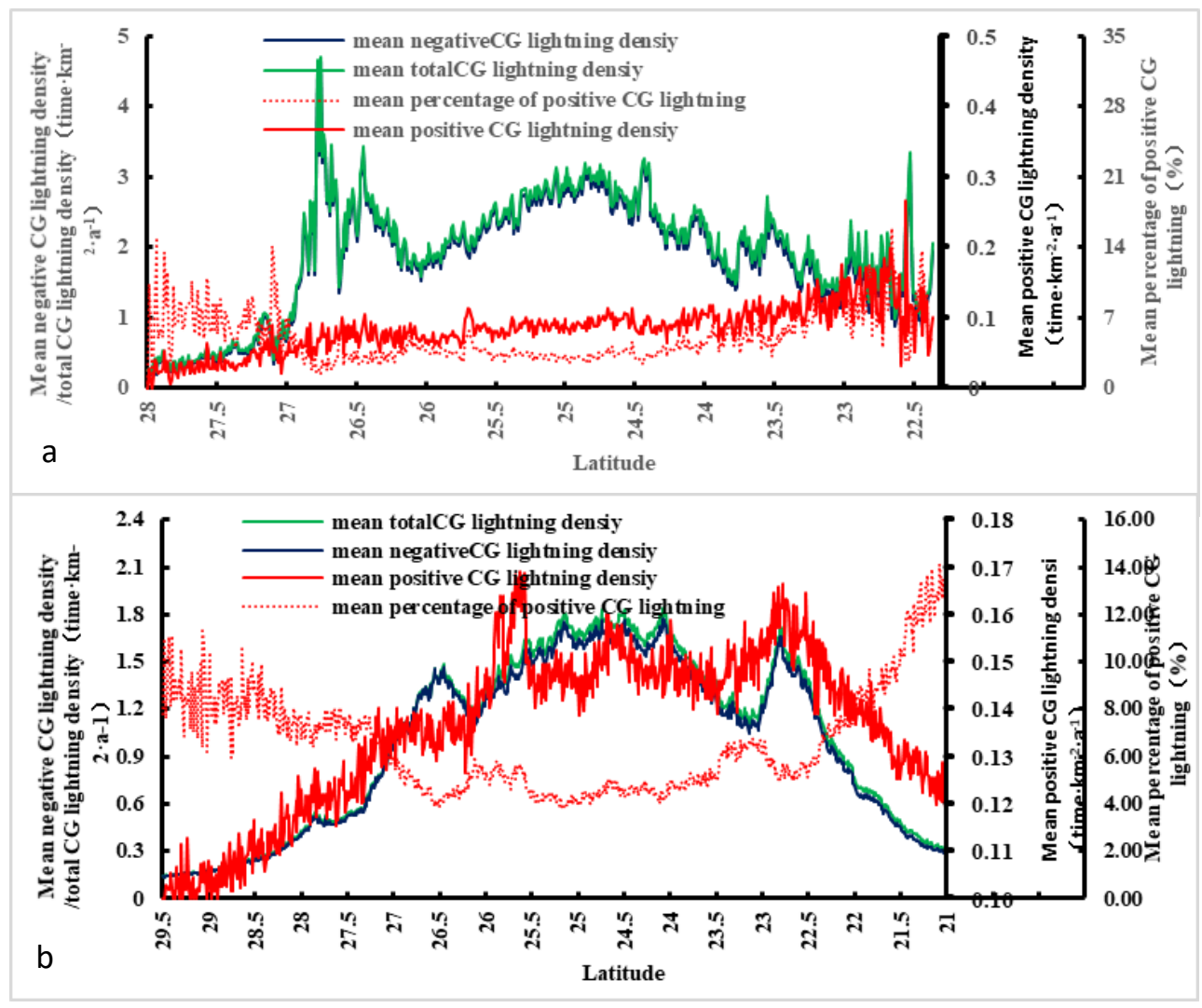

Figure 5. Variations in CG lightning densities and proportion of positive CG lightning over latitude in Yunnan Province. a: Entire province; b: Elevations between 1900 and $2100 \mathrm{~m}$ 
South of $26.7^{\circ} \mathrm{N}$, the average total/negative CG lightning density tended to increase with latitude, albeit with fluctuations, and three peaks were observed, essentially as already described, with the maximum density, 4.65 events $\mathrm{km}^{-2} \cdot \mathrm{a}^{-1}$, appearing at $26.7^{\circ} \mathrm{N}$. The average positive CG lightning density decreased with latitude with fluctuations. The variation in the proportion of positive CG lightning for latitudes between 1900-2100 m of elevation was consistent with the variation of the entire province.

\section{Topographic variation and the current intensity of CG lightning}

To determine the differences in CG lightning activity in the complex topography in Yunnan Province, the average intensity of positive/negative CG lightning of different elevations, terrain slope, and latitude were analyzed and are described as follows.

\section{Distribution of terrain and the current intensity of CG lightning}

Because the CG lightning activities in Yunnan mainly occurred between 800 and 3300 $\mathrm{m}$ above sea level, analysis on the effect of elevation on CG lightning intensity was limited in this range. Figure $6 a$ shows that the average current intensity of positive CG lightning was significantly greater than that of negative $\mathrm{CG}$ lightning. The average current intensity of positive CG lightning fluctuated within the range of $60-63 \mathrm{kA}$ as the elevation increased except for the abrupt increase at $1000 \mathrm{~m}$ above sea level. The current intensity of negative CG lightning initially decreased and subsequently increased with elevation and was negatively correlated with the variation in negative CG lightning density by elevation, with the minimum value (33.3 kA) appearing between 1900 and $2000 \mathrm{~m}$ where the peak value of negative CG lightning density appeared. The CG lightning activity in Yunnan Province was dominated by negative CG lightning, and the distribution of electrical charges in the thunderstorm cloud was negative-positive from the lower to the upper layers. The typical plateau topography facilitated rapid accumulation of the energy of low-layer negative electric charge and rapid formation of the CG lightning channel, causing the discharge process to occur when current intensity was still weak. This finding is basically consistent with $\mathrm{Li}$ (2011), who concluded that the variation in the current intensity of negative CG lightning and elevation tended to be stable at approximately $40 \mathrm{kA}$. In regions whose elevation $>2000 \mathrm{~m}$, as the elevation increased, the average current intensity of negative CG lightning increased slowly and linearly. CG lightning activity in high-elevation regions mainly occurred from local convection caused by solar radiation. As the elevation increased, water vapor content continuously decreased, and the energy required for accumulating electric charge in the cloud to form the CG lightning channel was high relative to that of the low-elevation regions, resulting in the linear increase of current intensity with elevation in highelevation regions. In lower regions with elevation $<1000 \mathrm{~m}$, compared with the special topography in Yunnan Province, descending motion dominated the airflow. Because of the higher elevation differences between the troposphere and ground level, thunderstorms could release their energy after fully maturing, causing the relatively strong current intensity of negative CG lightning in low-elevation regions.

\section{Distribution of terrain slope and the current intensity of CG lightning}

The topography of Yunnan Province has five major characteristics: plateau waviness, mountains speckled with valleys, staircase-like decreases, fault basins, and rivers and lakes dividing the region. Relatively large fluctuations in terrain slope are present in 
regions with different elevations, and Figure $6 b$ shows the variation in the average current intensity of CG lightning over terrain slope.

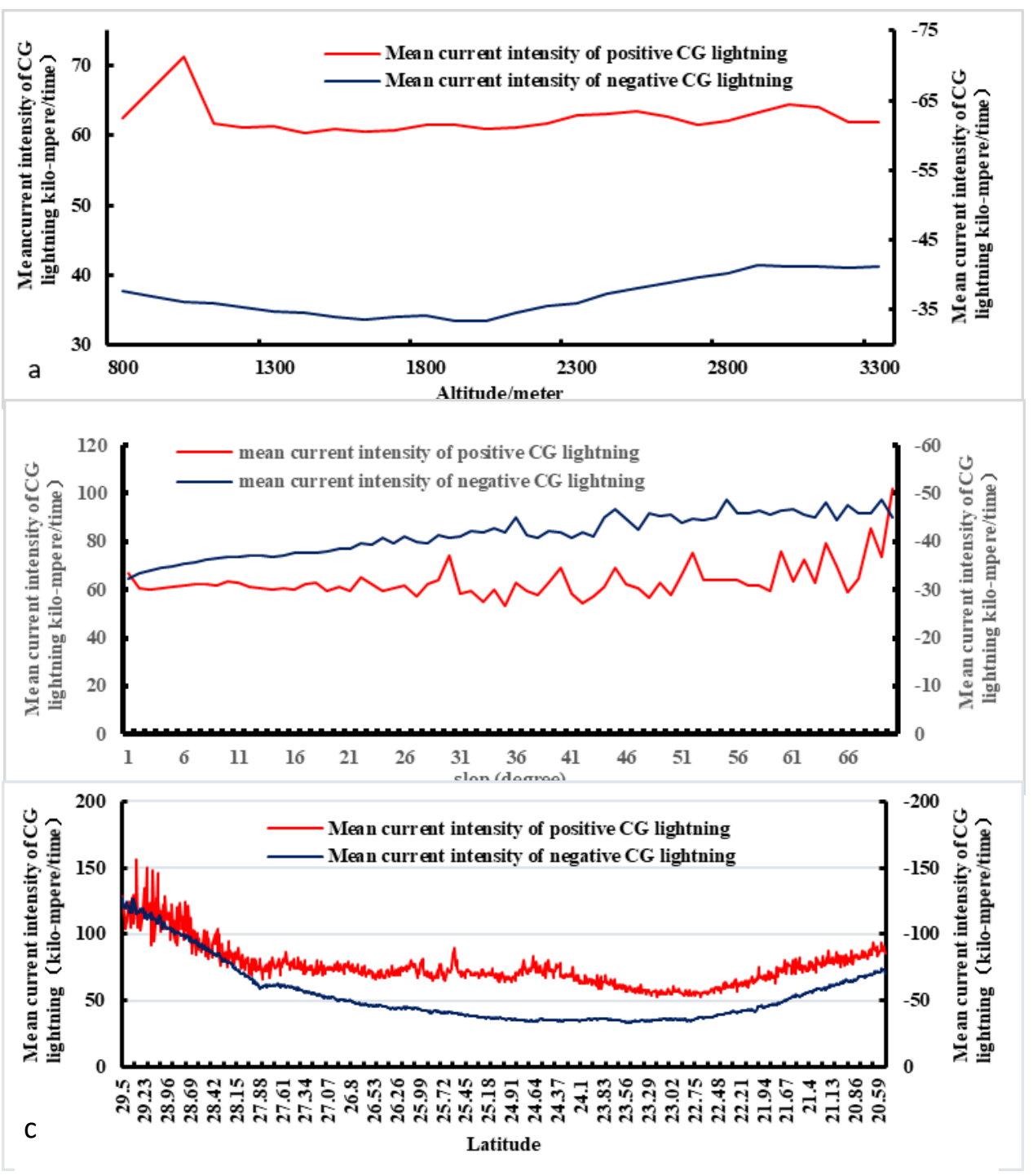

Figure 6. Variation in average current intensity of CG lightning with elevation and terrain slope from 2017-2016. a: variation in average current intensity of negative/positive CG lightning with elevation; $b$ : variation in average current intensity of negative/positive $C G$ lightning with terrain slope; $c$ : variation in average current intensity of negative/positive CG lightning with latitude

The average current intensity of negative CG lightning increased linearly with terrain slope, and in the basins and smooth regions with terrain slope $<20^{\circ}$, the average current intensity of negative CG lightning was $<40 \mathrm{kA}$. However, the average current intensity of negative CG lightning in regions with terrain slope $>20^{\circ}$ exhibited fluctuating increases, further indicating the dipolar characteristics of the electric charge distribution of thunderstorms of Yunnan Province, which means that the lower layers were mostly negatively charged, and as the terrain slope increased, the water vapor carried in the ascending airflow gradually decreased. Furthermore, negative electric charge 
accumulation increased the energy of CG lightning discharge, resulting in the linear increase of current intensity of negative CG lightning in regions with steep terrain slope. Additionally, the larger mountains in Yunnan Province are mostly distributed in the high-elevation regions. Generally, the current intensity of positive CG lightning was 20 $\mathrm{kA}$ stronger than that of the negative CG lightning, whereas the linear variation slope of average current intensity was less than that of negative CG lightning, indicating an obvious stronger energy requirement for positive lightning discharge in the upper troposphere. In areas of flat terrain with slopes of $<30^{\circ}$, the average current intensity of positive CG lightning fluctuated slightly between 60 and $63 \mathrm{kA}$. Although the average current intensity of positive CG lightning fluctuated between 53 and $75 \mathrm{kA}$ in regions where the terrain slope was between $30^{\circ}$ and $60^{\circ}$, which was related to the drastic change in elevation in these regions. The average current intensity of positive $\mathrm{CG}$ lightning in regions with terrain slope $>60^{\circ}$ increased significantly. Both the current intensities of positive and negative CG lightning showed a significant linear positive change with variation in terrain slope. Where slopes are steeper, more energy is required to generate CG lightning, resulting in more infrequent CG lightning but with stronger current intensity on steep slopes. The current intensity of positive CG lightning was larger than that of negative CG lightning but the variable slope was smaller. The center of negative electric charge was located in the lower layer of the thunderstorm cloud, and negative CG lightning was more easily affected by topography.

\section{Distribution of latitude and the current intensity of CG lightning}

The distribution of electric charge in cumulonimbus cloud was as follows: the lower layer between 0 and $-20^{\circ} \mathrm{C}$ was the negative charge accumulation area, and the higher layer between -20 and $-50{ }^{\circ} \mathrm{C}$ was the positive accumulation area. For a given amount of electric charge, a pilot stroke with a small distance to the ground could reach the ground to form a CG lightning bolt easily; the energy requirement was small, and the chance of CG lightning formation was small if the distance to the ground was large and the energy required for $\mathrm{CG}$ lightning discharge was relatively large. The current intensity of positive CG lightning in Yunnan Province was significantly larger than that of the negative CG lightning because the number of return stroke of positive CG lightning was significantly less than that of the negative CG lightning. The current intensity decreases rapidly due to multiple discharges caused by multiple flashbacks (Xie, 2013). The average current intensity of positive/negative CG lightning initially decreased and subsequently increased as latitude increased. In the low latitude regions south of $23^{\circ} \mathrm{N}$, the average current intensity of positive CG lightning decreased from $85 \mathrm{kA}$ to $55 \mathrm{kA}$ as latitude increased. Regions between $23^{\circ} \mathrm{N}$ and $27^{\circ} \mathrm{N}$ in Yunnan are areas of frequent intense convection, which significantly increased the development of positively charged particles in the cloud and caused the average current intensity of positive CG lightning to increase with fluctuations. The regions north of $27.8^{\circ} \mathrm{N}$ in Yunnan Province include the snow mountains in the northwest with elevations $>3000 \mathrm{~m}$ and the river valleys with elevations $<1000 \mathrm{~m}$, where the terrain slope was steeper and the amount of CG lightning was lower; thus, the current intensity of CG lightning increased linearly with latitude. The variation in average current intensity of negative $\mathrm{CG}$ lightning with latitude fluctuated less. In the low latitude regions, the $0{ }^{\circ} \mathrm{C}$ level height was relatively high, and the average current intensity was stronger. Additionally, within the range $23^{\circ} \mathrm{N}-27^{\circ} \mathrm{N}$, the convergence of the cold and warm air caused severe convection, reducing the $0{ }^{\circ} \mathrm{C}$ level height; therefore, the average current intensity weakened obviously to 
approximately $-35 \mathrm{kA}$, and the negative CG lightning current intensity increased linearly to $100 \mathrm{kA}$ where latitude $>27^{\circ} \mathrm{N}$.

The current intensity of CG lightning in Yunnan Province was obviously affected by the combination of topography, terrain slope, and latitude. South of $23^{\circ} \mathrm{N}$, the topography was mainly basins, river valleys, and hills with steep terrain slope, low elevation, and high $0{ }^{\circ} \mathrm{C}$ level height; thus, the current intensity of $\mathrm{CG}$ lightning was relatively strong. Regions between $23^{\circ} \mathrm{N}$ and $27^{\circ} \mathrm{N}$ were mainly basins and hills with less steep terrain slope and elevation of approximately 1900-2100 m; because of the decrease in $0{ }^{\circ} \mathrm{C}$ level height caused by more active cold air, the current intensity of CG lightning was relatively weak. North of $27^{\circ} \mathrm{N}$ were the snowy mountains with high elevation and steep terrain slope and river valleys with low elevation and steep terrain slope where forming convection currents was more difficult; therefore, the current intensity of CG lightning was obviously stronger.

\section{Relationship between CG lightning activity and topography in the central Yunnan region}

Previous analysis revealed that CG lightning activity was highly concentrated in basins and placid hills whose elevation was between 1500 and $2300 \mathrm{~m}$ with terrain slope $<30^{\circ}$. Of these areas, the central Yunnan region was the most active for CG lightning activity. In this study, CG lightning data on more than 20,000 grids with a definition of $0.01^{\circ} \times 0.01^{\circ}$ ranging within $101.6^{\circ} \mathrm{N}-103.6^{\circ} \mathrm{E}$ and $24.5^{\circ} \mathrm{N}-25.5^{\circ} \mathrm{N}$ were chosen and analyzed.

Figure $7 a$ shows the variation in CG lightning density over elevation in central Yunnan and reveals that within the elevation range of $1100-2700 \mathrm{~m}$, the average CG lightning density was positively linearly correlated with elevation $(R=0.65)$ because as elevation increased, the CG lightning density increased.

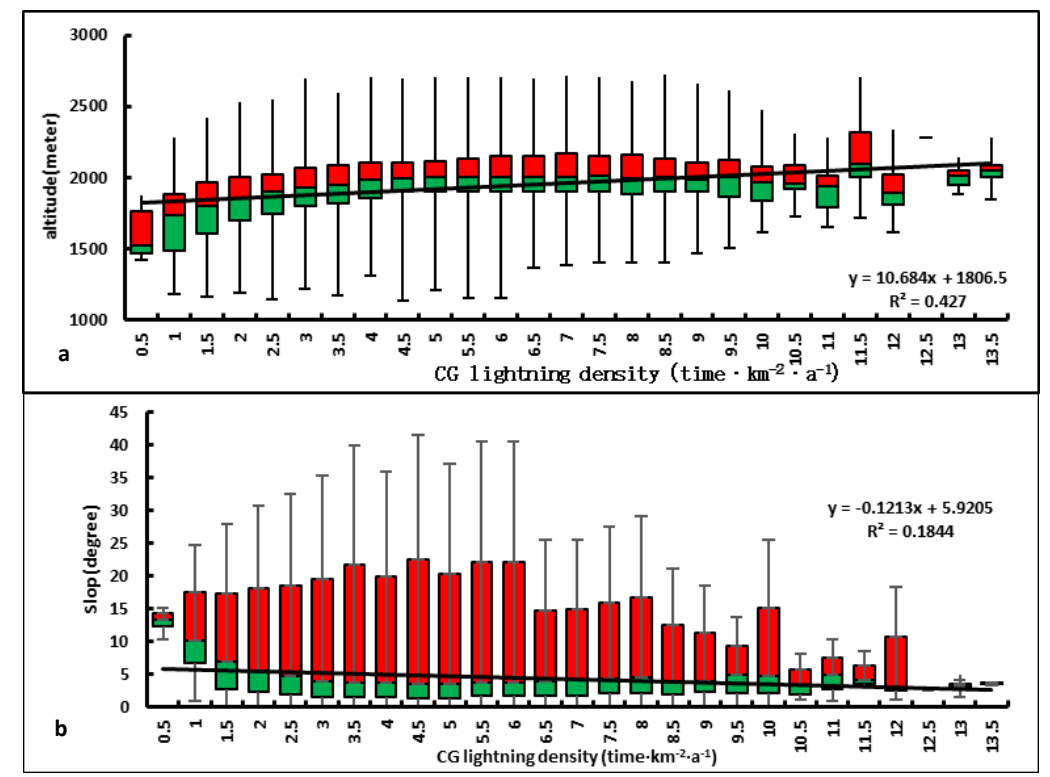

Figure 7. Correlation between CG lightning densities with elevation and terrain slope in grid of $0.01^{\circ} \times 0.01^{\circ}$ and using 0.5 time $\cdot \mathrm{km}^{-2} \cdot a^{-1}$ as intervals in central Yunnan. The variation range of $C G$ lightning densities was $0.5-13.5$ time $\cdot \mathrm{km}^{-2} \cdot \mathrm{a}^{-1}$; a: the correlation parameter of average CG

lightning densities and elevation was $0.65 ; b$ : the correlation parameter of $C G$ lightning densities and terrain slope was 0.43 
Furthermore, areas with a lower CG lightning density were mainly concentrated within the elevation range of 1400-1800 m, whereas areas with a higher CG lightning density were mainly concentrated within the elevation range of 1800-2000 m. However, the CG lightning density was inversely correlated with the change in the terrain slope $(R=$ 0.43). CG lightning activity with a density $<6$ events $\cdot \mathrm{km}^{-2} \cdot \mathrm{a}^{-1}$ was vastly spread between terrain with slope ranging $3^{\circ}-24^{\circ}$, whereas $C G$ lightning activity with density $>10$ events $\cdot \mathrm{km}^{-2} \cdot \mathrm{a}^{-1}$ was mainly distributed over the terrain with slope ranging $2^{\circ}-12^{\circ}$.

The variation characteristics of current intensity of CG lightning over elevation in this region were generally the same as the variation characteristics of the entire province (see Fig. 7b); the current intensity of negative CG lightning was weaker, and the positive current intensity was approximately twice the negative current intensity. Additionally, as the elevation increased, the current intensity increased slowly. The variation in current intensity of CG lightning over terrain slope in this region was relatively complicated because the average negative current intensity initially increased and subsequently decreased, whereas the current intensity of positive CG lightning stabilized at $53-56 \mathrm{kA}$ with terrain slope $<20^{\circ}$ and fluctuated violently with terrain slope $>20^{\circ}$ (Fig. 8).

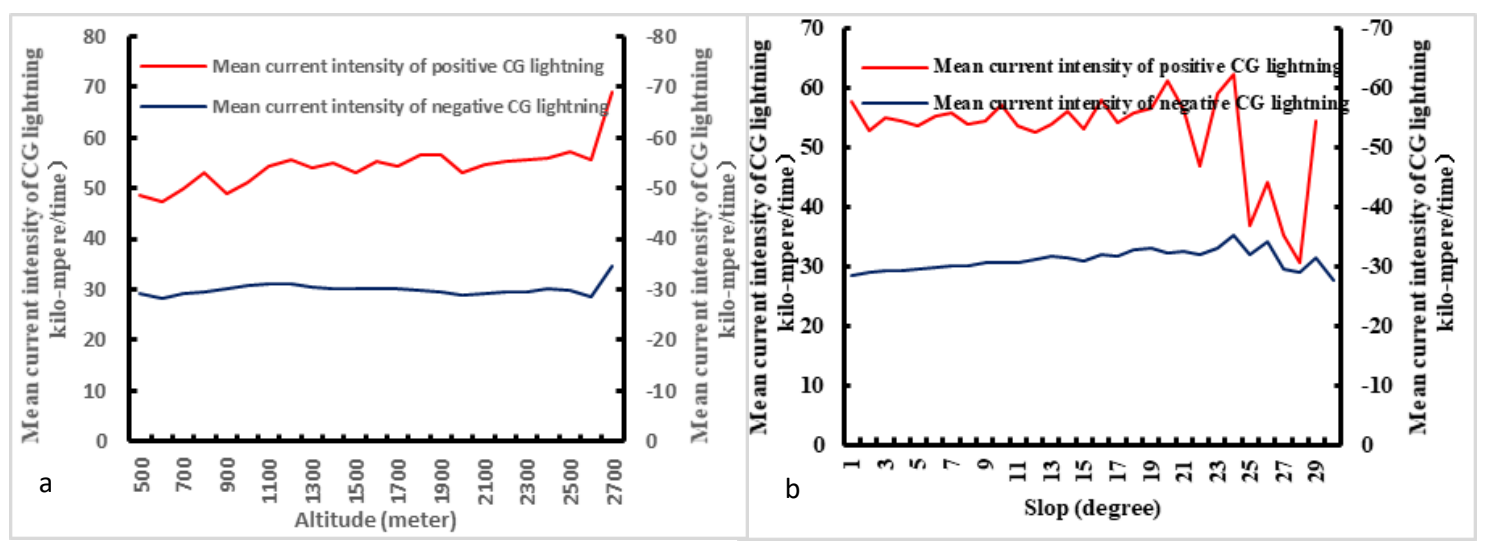

Figure 8. Correlations between average current intensity of CG lightning, elevation, and terrain slope in $0.01^{\circ} \times 0.01^{\circ}$ intervals in the central Yunnan region. a: Variation in current intensity with elevation; $b$ : Variation in current intensity with terrain slope

\section{Relationship between CG lightning activity and topography in specific regions}

CG lightning data, topography, and terrain slope of fixed zonal and meridional crosssections along the central Yunnan region where CG lightning activity was dense were selected for further analysis. The east-west cross-section of $25.2^{\circ} \mathrm{N}$ was chosen for analysis of the synoptic systems and CG lightning activity, whereas the influence of the greater elevation and slope difference was analyzed using the north-south cross-section of $102.5^{\circ} \mathrm{E}$. In Figure $9 a$, from east to west in the zonal cross-section, the elevation remained stable at approximately $2000 \mathrm{~m}$ and the $\mathrm{CG}$ lightning density in $101.6^{\circ} \mathrm{E}-$ $103.6^{\circ} \mathrm{E}$ exhibited clear peaks, indicating that the main synoptic systems and the $\mathrm{CG}$ lightning densities exhibited a positive correlation within this longitude range. The CG lightning densities and terrain slope of the corresponding area exhibited a significant inverse correlation (see Fig. 9c) as the CG lightning densities increased and the terrain slope decreased, and vice versa. From the south to the north in the meridional cross- 
section, the elevation fluctuated and increased from $23.4^{\circ} \mathrm{N}-25.5^{\circ} \mathrm{N}$ (see Fig. $9 b$ ) and exhibited a positive correlation with the corresponding CG lightning densities; however, the terrain slope initially increased and subsequently decreased within this area (see Fig. 9d) and was inversely correlated with the CG lightning densities. In summary, the CG lightning activity in Yunnan had a favorable correlation with the topography and terrain slope, particularly in the area between $101.6^{\circ} \mathrm{E}-103.6^{\circ} \mathrm{E}$ and $24^{\circ} \mathrm{N}-25.5^{\circ} \mathrm{N}$ because the CG lightning densities were correlated with elevation and inversely correlated with terrain slope. Furthermore, the effect of the large-scale strong convective synoptic systems was most significant in this same area.

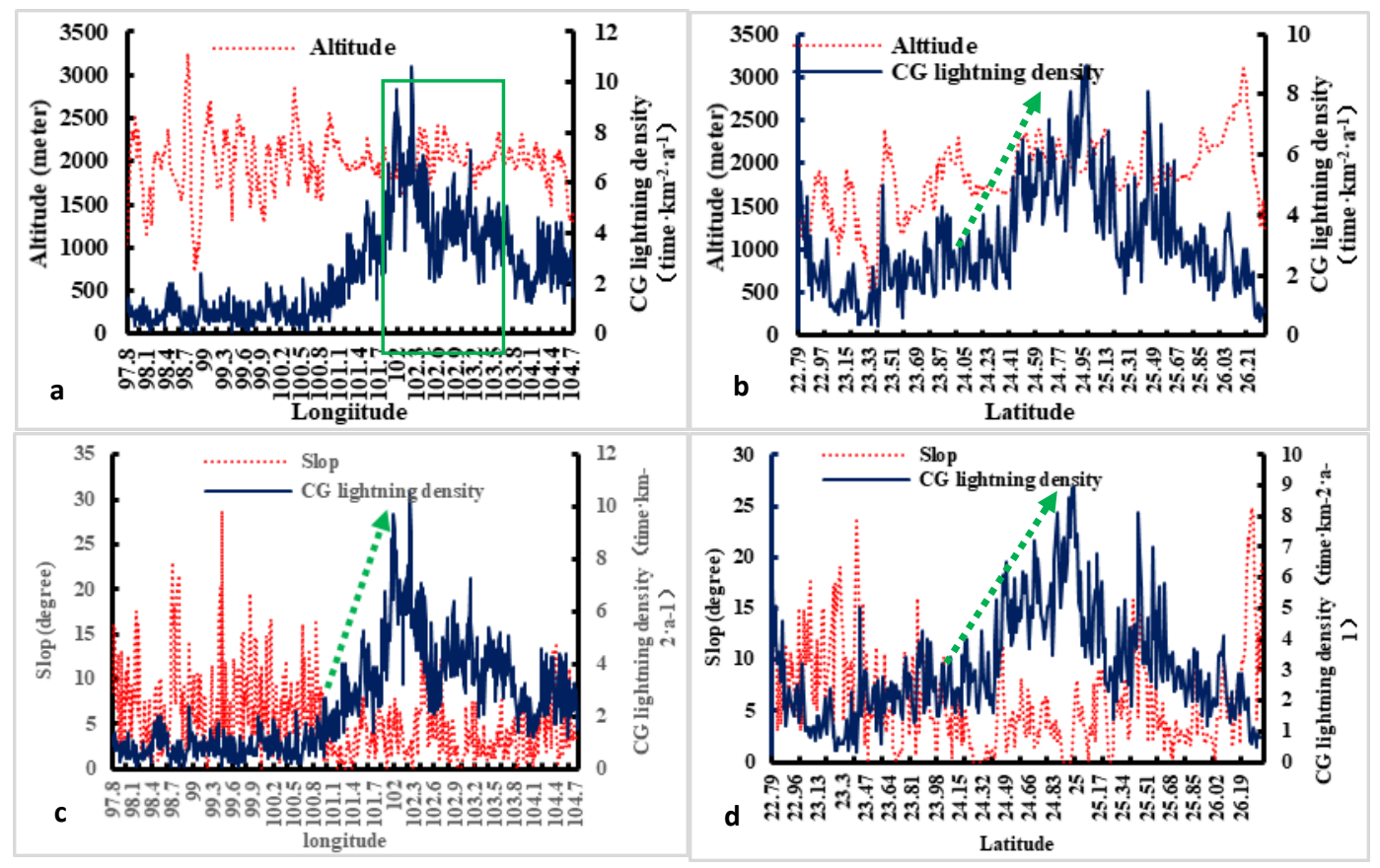

Figure 9. Relationship between CG lightning densities and elevation and terrain slope along the zonal cross-section of $25.2^{\circ} \mathrm{N}$ and the meridional cross-section of $102.5^{\circ} \mathrm{E}$. a: CG lightning densities and elevation in cross-section of $25.2^{\circ} \mathrm{N} ; b$ : CG lightning densities and elevation in cross-section of $102.5^{\circ} \mathrm{E}$; c: CG lightning densities and terrain slope in cross-section of $25.2^{\circ} \mathrm{N}$; $d$ : CG lightning densities and terrain slope in cross-section of $102.5^{\circ} \mathrm{E}$

\section{Hourly variation characteristics of CG lightning activity at different elevations}

Figure 10 shows the diurnal variation in the average CG lightning frequency in Yunnan from 2007 to 2016 with 100-m increments of elevation to further elucidate the contributions of the topography. The dense area of CG lightning is an elliptical shape 600-3500 $\mathrm{m}$ above sea level, indicating that as the elevation increases, the effect of the large-scale convection systems decreases. Low-elevation areas dominated by topography $(<600 \mathrm{~m})$ were night thunderstorm hotspots and generally occurred between 21:00 and dawn on the subsequent day. Affected by the topography, terrain slope, and elevation, the main forming and enhancement period of large-scale strong convective systems in Yunnan Province was between afternoon and midnight, which corresponded to the period of enhancement of convection caused by solar radiation (Xu et al., 2011; Zhang et al., 2013). The double influence of topography and large-scale strong convection system aggravated the CG lightning activity, resulting in the consistent 
large-amplitude variation characteristics of CG lightning in Yunnan Province at 600$3500 \mathrm{~m}$ above sea level, and in low (high) elevation areas where elevation was lower than $600 \mathrm{~m}$ (higher than $3500 \mathrm{~m}$ ), the effect of topography on CG lightning activity was more significant.

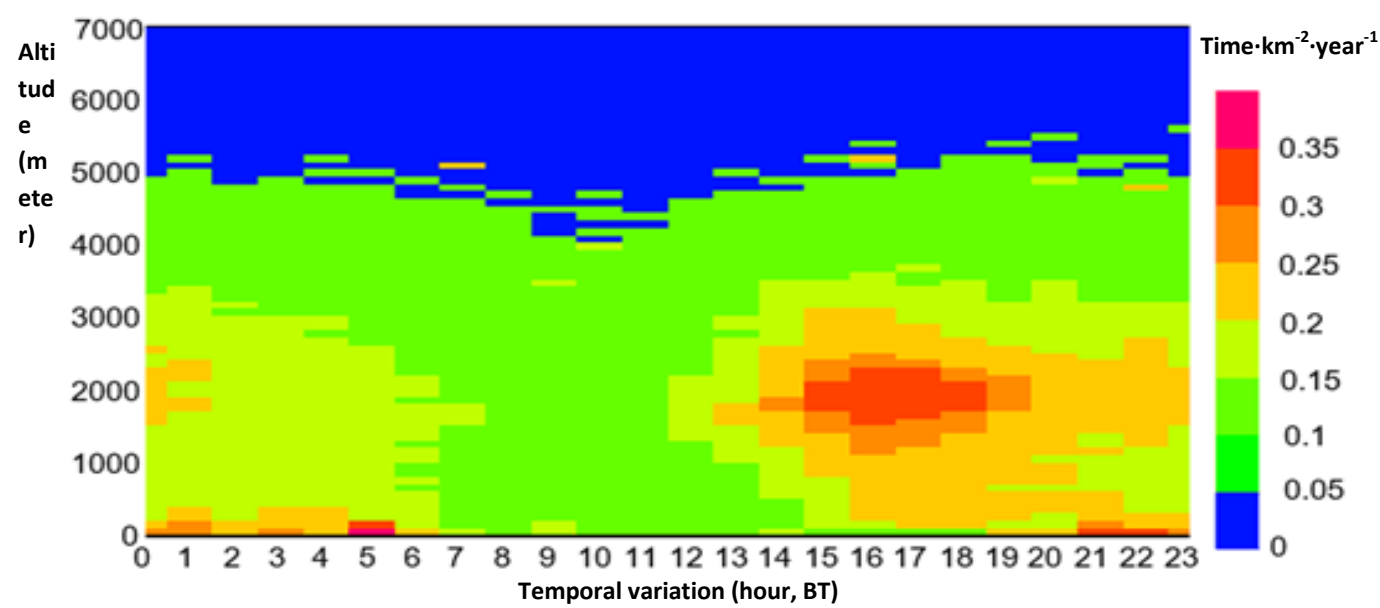

Figure 10. Diurnal variation of the average CG lightning frequency (with elevation range from $0-7000 \mathrm{~m}$ and using $100 \mathrm{~m}$ as intervals)

\section{Discussion and conclusion}

CG lightning activity was normally distributed along the variation in elevation, which centered on $2000 \mathrm{~m}$ above sea level and decreased on both sides and which exhibited linear inverse correlation characteristics between terrain slopes because when the terrain slope is less steep, the CG lightning activity is relatively dense. Regions of elevation <2300 m were generally basins, river valleys, or hills, and their corresponding CG lightning densities were approximately twice as high as those in regions whose elevation $>2300 \mathrm{~m}$. Within these regions, the uplift effect in areas with terrain slope from $30^{\circ}$ to $59^{\circ}$ could cause smaller peaks of CG lightning activity, and no significant CG lightning activity was observed in areas with terrain slope $>60^{\circ}$. However, in regions where elevation $>2300 \mathrm{~m}$, the topography was mainly basins and large mountains. Furthermore, a blank zone was observed in areas with terrain slope $40^{\circ}-50^{\circ}$, and only sporadic CG lightning activity was observed on the windward side of mountain areas with terrain slope $>60^{\circ}$, indicating the substantial influence of topography on CG lightning activity. Furthermore, the results showed that the CG lightning activity in Yunnan Province initially increased and subsequently decreased with the increase of latitude, indicating that the influence of topography and large-scale synoptic systems was larger than the influence of variations in solar radiation along latitude.

The electric charge distribution in thunderstorms in Yunnan exhibited a typical positive dipole characteristic, and the average current intensity of positive CG lightning was significantly greater than that of negative CG lightning. Furthermore, the positive charge was located in the upper layers of the thunderstorm cloud; thus, the average current intensity fluctuated stably within a small range, 60-63 kA, as the elevation varied and the current intensity of negative CG lightning initially decreased and subsequently increased with the change in elevation and was inversely correlated with 
CG lightning densities. The current intensity of CG lightning increased linearly with the increase of terrain slope, and the slope of variation of positive CG lightning was less than that of negative CG lightning, indicating that the effect of topography on the current intensity of negative CG lightning was more significant than that of the positive CG lightning in lower layers. The variation in intensity of CG lightning with latitude was inversely correlated with the variation in CG lightning density. South of $23^{\circ} \mathrm{N}$, the current intensity was strongly affected by solar radiation and the relatively high $0{ }^{\circ} \mathrm{C}$ level height and greatly affected by the uplift effect of the large mountains. The current intensity was relatively strong north of $27^{\circ} \mathrm{N}$. Within $23^{\circ} \mathrm{N}-27^{\circ} \mathrm{N}$, affected by the impact of the large-scale synoptic systems and the low $0{ }^{\circ} \mathrm{C}$ level height, the current intensity was relatively weak.

The present study on the relationship between CG lightning activity and topography in central Yunnan, which is greatly influenced by large-scale synoptic systems, found a favorable positive correlation between the CG lightning density and elevation in the range 1100-2700 m; it was inversely correlated with the variation in terrain slope steeper than $40^{\circ}$. The variation in current intensity was essentially the same as reported in previous studies.

Analysis of CG lightning activity and topography in zonal and meridional crosssections revealed that the CG lightning activity was positively correlated with elevation less than $2500 \mathrm{~m}$, but was inversely correlated with terrain slope less than $<15^{\circ}$.

Acknowledgements. Funded by the National Natural Science Foundation of China (41641044) and Technological and Planning Project of Yunnan Province (2015FB166, 2016RA096).

\section{REFERENCES}

[1] Biagi, C. J., Cummins, K. L., Kehoe, K. E., Krider, E. P. (2007): National Lightning Detection Network (NLDN) performance in southern Arizona, Texas and Oklahoma in 2003-2004. - J. Geophys. Res. 112: D05208.

[2] Bourscheidt, V. Pinto Junior, O., Naccarato, K. P., Pinto, I. R. C. A. (2009): The influence of topography on the cloud-to-ground lightning density in South Brazil. Atmospheric Research 91(2009) 508-513.

[3] Chen, W. M. (2003): Theory of Lightning. - China Meteorological Press, Beijing.

[4] Egger, J., Hoinka, K. P. (1992): Fronts and orography. - Meteor. Atmos. Phys. 48: 3-36.

[5] Ezcurra, A., Areitio, J., Herrero, I., (2002): Relationships between cloud-to-ground lightning and surface rainfall during 1992-1996 in the Spanish Basque Country area. Atmos. Res. 61(3): 239-250.

[6] Jayaratne, E. R., Kuleshov, Y. (2006): Geographical and seasonal characteristics of the relationship between lightning ground flash density and rainfall within the continent of Australia. - Atmos. Res. 79: 1-14.

[7] Li, W. L., Qie, X. S., Fu, S. M. (2016): Simulation of quasi-linear mesoscale convective systems in northern China: Lightning activities and storm structure. - Advances in Atmospheric Sciences 33(1): 85-100.

[8] Li, Z. (2011): Characteristics of Lightning Activity in Chongqing Affected by The Analysis of Underlying Surface. - Master of Science Thesis, Nanjing University of Information Engineering.

[9] Ma, M., Tao, S. C., Zhu, B. Y., Lv, W. T. (2004): The climate distribution of lightning density in China and surrounding areas observed by satellites. - Science in China Ser. D Earth Sciences 34(4): 298-306. 
[10] Monmonier, M. S. (1982): Computer-Assisted Cartography. - Prentice-Hall, Englewood Cliffs, NJ.

[11] Pinto Jr., O., Pinto, I. R. C. A., Gomes, M. A. S. S., Vitorello, I., Padilha, A. L., Diniz, J. H., Carvalho, A. M., Cazetta Filho, A. (1999): Cloud-to-ground lightning in Southeastern Brazil in 1993. - 1. Geographical distribution. - J. Geophys. Res. 104(D24): 3136931379.

[12] Qie, X. S., Zhang, T. L., Zhang, G. S. (2009): Electrical characteristics of thunderstorms in different plateau regions of China. - Atmospheric Research 91(2-4): 244-249.

[13] Qie, X. S., Zhou, D., Tie, Y. (2003): Global lightning activities and their regional differences observed from the satellite. - Chinese Journal of Geophysics 46(6): 743-751.

[14] Qie, X. S., Wang, Z. C., Wang, D. F. (2013): Characteristics of positive cloud-to-ground lightning in Da Hinggan Ling forest region at relatively high latitude, northeastern China. - Journal of Geophysical Research-Atmospheres 118(24): 13393-13404.

[15] Schulz, W., Diendorfer, G., (1999): Lightning characteristics as a function of altitude evaluated from lightning location network data. - Proceedings of the International Conference on Lightning and Static Electricity (ICOLSE). Society of Automotive Engineers, Toulouse, France.

[16] SEMC (2002): Rio Grande do Sul: atlas eólico. - Secretaria de Energia, Minas e Comunicações, Brasil.

[17] Smith, R. B., (1979): The Influence of Mountains on the Atmosphere. - In: Saltzman, B. (ed.) Advances in Geophysics. Academic Press Inc., New York, pp. 87-230.

[18] Soula, S., Chauzy, S., (2001): Some aspects of the correlation between lightning and rain activities in thunderstorms. - Atmos. Res. 56: 355-373.

[19] Tong, H. W., Fan, G. W., Wang, H. T. (2008): The characteristics of the lightning activity and its relationship with topography and climate in Zhejiang province. - Power System Technology 6: 9-100.

[20] Wagner, G., Fuelberg, H. E., Kann, D., Wynne, R., Cobb, S., (2006): A GIS-based approach to lightning studies for West Texas and New Mexico. - Proceedings of the Second Conference on Meteorological Applications of Lightning Data. American Meteorological Society, Atlanta.

[21] Wang, L. L., Qie, X. S., Shen, M. F. (2016): Simulation of quasi-linear mesoscale convective systems in northern China: lightning activities and storm structure. Advances in Atmospheric Sciences 33(1): 85-100.

[22] Xie, Y. R., Xu, K., Zhang, T. F., Liu, X. T. (2013): Five-year study of cloud-to-ground lightning activity in Yunnan province, China. - Atmospheric Research 129-130: 49-57.

[23] Xu, M. L., Duan, X., Qi, M. H. (2011): Yunnan Weather Forecaster Handbook. - China Meteorological Press, Beijing.

[24] Zajac, B. A., Rutledge, S. A., (2001): Cloud-to-ground lightning activity in the contiguous United States from 1995 to 1999. - Mon. Wea. Rev. 129 5): 999-1019.

[25] Zhang, T. F., Yin, L. Y., Xie, Y. R. (2013): Study and application of lightning monitoring and warning method in low latitude plateau area. - China Meteorological Press, Beijing. 